\title{
GAMIFICATION: ADAPTASI GAME DALAM DUNIA PENDIDIKAN ${ }^{1}$
}

\author{
Eric Kunto Aribowo \\ erickunto@unwidha.ac.id
}

\begin{abstract}
Already there are many voices that admit the need and urgency that the school be appropriated of the digital technology and transform of radical way its pedagogical practice. In this paper, the game through gamification mechanism's described in order to demonstrate how the game is more able to attract the engagement of the players. The elements of gamification indicates how to motivate users through points, badges, levels, and leaderboards.
\end{abstract}

Keywords: gamification, engagement, motivation

Abstraksi

Sudah ada banyak pendapat yang mengakui kebutuhan dan urgensi bahwa sekolah harus disesuaikan dengan teknologi digital dan mengubah cara praktik pedagogisnya secara radikal. Dalam tulisan ini, game melalui mekanisme gamification diuraikan dalam rangka menunjukkan bagaimana game lebih mampu menarik antusiasme pemainnya. Unsur-unsur gamification ternyata merujuk pada bagaimana memotivasi pengguna melalui points, badges, levels, dan leaderboards.

Kata kunci: gamification, antusiasme, motivasi

\section{A. Pendahuluan}

Jamak ditemui bahwa dalam dunia pendidikan kita terdapat berbagai macam problematika yang harus dipecahkan. Permasalahan ini barangkali sudah menjadi menu favorit yang senantiasa kita jumpai mulai dari tingkat dasar, menengah, hingga pendidikan tinggi. Sebut saja fenomena-fenomena yang lazim didapati sebagaimana saya sebut berikut. (1) Biasanya peserta didik hanya diberitahu apa yang harus dilakukan tanpa memahami manfaat yang lebih besar dari apa yang mereka kerjakan. (2) Biasanya sebagian besar siswa tidak menyadari seberapa besar kemajuan yang mereka peroleh hingga mereka mengambil tes atau ujian. (3) Terkadang sulit bagi siswa untuk mengikuti metode belajar baru yang telah disiapkan. (4) Sangat sulit bagi peserta didik untuk mengatasi pengalaman yang kurang menyenangkan, seperti kegagalan dalam ujian dan hasil kinerja yang rendah. (5) Dalam pendidikan, taruhan kegagalan sangat beresiko tinggi dan siklus umpan balik terhadap siswa relatif membutuhkan waktu yang lama. (6) Dalam lingkungan pendidikan, pengakuan terhadap sebuah keberhasilan (penguatan atau reinforcement) sebagian besar hanya disediakan oleh guru/instruktur, sedangkan peran peserta didik lain sangat terbatas.

Hal-hal tersebut di atas, sebenarnya sudah diupayakan jalan keluarnya melalui penelitianpenelitian yang bermunculan pada dekade terakhir ini. Sayangnya, penelitian yang ada di Indonesia masih berorientasi pada bagaimana cara mengupayakan peningkatan prestasi peserta didik serta menciptakan

\footnotetext{
${ }^{1}$ Aribowo, E. K. (2014) “Gamification: Adaptasi Game dalam Dunia Pendidikan,” in Saputro, A. N. C. dan Winarno (ed.) Pengembangan Profesi Guru dan Dosen melalui Penulisan Jurnal Ilmiah Pendidikan. Surakarta: Pelangi Press, hal. 121131.
} 
sebuah lingkungan belajar yang lebih menyenangkan. Adapun untuk peningkatan motivasi belajar siswa masih terbatas pada permainan-permainan sederhana atau tradisonal (baca Nugrahani, 2007; Arum dan Achmad, 2012; serta Nugroho, dkk., 2013). Permainan digital seperti game belum pernah ditemukan dalam usaha meningkatkan keaktifan siswa dalam pembelajaran. Padahal, tidak perlu kita perdebatkan lagi bahwa game sudah seperti zat aditif bagi anak-anak yang mayoritas berperan sebagai pelajar.

Gamification merupakan suatu hal yang baru yang merupakan adopsi dari mekanisme video game pada bidang-bidang lain. Sejak tahun 2011 hingga saat ini jumlah tulisan yang berkaitan dengan tema ini melonjak tajam (lihat ulasan Hamari, dkk., 2014) di basis data Scopus, ScienceDirect, EBSCOHost, Web of Science, ACM Digital library, AISel, Google Scholar, and Proquest. Ulasan mereka mengindikasikan bahwa gamification memberikan efek yang positif. Bagaimanapun juga, besarnya efektivitas tersebut tergantung pada seberapa besar konteks gamification yang diterapkan, yang juga digunakan oleh para penggunanya.

Telah ada peningkatan dalam penelitian di berbagai ranah di mana kombinasi antara teknologi dan desain game telah dieksplorasi sebagai sarana untuk memotivasi orang-orang dalam berbagai aspek kehidupan mereka. Zicherman (2011) telah mendesain sistem yang diadopsi dari mekanisme game untuk meningkatkan produktivitas para karyawan.

Selain itu, desain pembelajaran di pendidikan tinggi melalui gamification telah dilaksanakan dengan apik oleh O'Donovan, dkk. (2013). Melalui Vula -game daring yang didesain olehnya- beliau berusaha untuk meningkatkan kehadiran dosen, pemahaman materi, skill mahasiswa dalam memecahkan masalah, dan antusiasme. Dengan sistem poin (XP) yang diterapkan berdasar pada ketercapaian materi (10XP untuk capaian 70-79\%; 20XP untuk 8o-89\%; dan 3oXP untuk 9o-100\%) antusiasme mahasiswa dapat diraih. Ditambah lagi, leaderboards disediakan untuk menampilkan deretan 20 nama mahasiswa peringkat teratas. Bahkan, untuk 10 mahasiswa terbaik memenangkan kaos yang berlogo game tersebut. Uji coba tersebut membuktikan bahwa keaktifan siswa dan dosen meningkat. Artinya, pendekatan gamification merupakan pendekatan yang efektif dalam ruang lingkup dunia pendidikan. Teknik gamification yang digunakan pada desain pembelajaran secara signifikan meningkatkan pemahaman dan secara khusus pada antusiasme pebelajar.

Melalui tulisan ini, penulis mencoba memaparkan bagaimana gamification dapat dimanfaatkan untuk menjawab enam permasalahan yang telah dikemukakan di awal dengan jalan menguraikan kelebihan apa yang ada pada teknik ini -yang dapat dimanfaatkan dalam proses pembelajaran dan mampu memotivasi peserta didik. Selain itu, penulis juga mencoba mengagas sebuah metode pembelajaran yang diadaptasikan dari game yang dapat membuat siswa menjadi bersemangat, antusias, dan termotivasi.

\section{B. Pembahasan}

Gamification merupakan kosakata dalam bahasa Inggris yang berasal dari kata "game" dan sufiks ication yang bermakna 'making or causing something'. Jull (2003) memberikan definisi yang eksplisit tentang game yang berhubungan dengan proses belajar. Menurutnya:

"a game is a rule-based formal system with a variable and quantifiable outcome, where different outcomes are assigned different values, the player exerts effort in order to influence the outcome, the player feels attached to the outcome, and the consequences of the activity are optional and negotiable."

Secara sederhana gamification merujuk pada "the use of game elements in contexts that originally had no link to game-related." Sebagaimana diungkapkan oleh Erin (2013). Dalam pengertian lain, 
gamification juga diartikan sebagai "a process of enhacing a service with affordances for gameful experiences in order to support user's overall value creation." (Houtari dan Hamari, 2012). Gamification juga dimaknai sebagai "the addition of elements commonly assocciated with games (e.g. game mechanics) to an educational or training program in order to make the learning process more engaging." (Landers dan Rachel, 2011).

Gamification, atau penggunaan elemen permainan dalam konteks non-game, telah menjadi pendekatan yang semakin populer dalam rangka meningkatkan antusiasme pengguna dalam berbagai konteks, termasuk produktivitas karyawan (Landers dan Rachel, 2011; Harris, 2014), penjualan (Houtari dan Hamari, 2012), dan pendidikan (Fitz-Walter, dkk., 2012; Glover 2013; Gonzalez dan Area, 2013; Miller, 2013; Reiners, dkk., 2012, Ormsby dkk., 2012). Pada pembahasan awal, akan kami menunjukkan bahwa gamification dapat digunakan untuk meningkatkan keterlibatan siswa dan pembelajaran dengan pengujian aplikasi mobile game. Pernyataan-pernyataan yang hadir kami buktikan berdasarkan eksplorasi terhadap empat mobile game ${ }^{2}$ yang diunduh dari appstore: (a) The Sims ${ }^{T M}$ FreePlay $^{3}$, (b) Bridge Constructions ${ }^{4}$, (c) Hay Day $^{5}$, dan (d) Dental Surgery.

Sebelum memaparkan kelebihan mengenai gamification lebih jauh, ada baiknya kami sajikan unsur ataupun elemen yang menjadi karakteristik gamification. Unsur-unsur ini kami adaptasikan dari berbagai sumber (yang kami rujuk dari rerefensi yang tercantum pada daftar pustaka) serta melakukan cek silang terhadap keempat game yang digunakan dalam tulisan ini.

Yang perlu menjadi perhatian penting adalah game yang hadir di era saat ini telah mengalami evolusi sedemikian rupa sehingga sangatlah berbeda dengan game yang lahir pada tahun 1980-an hingga 199o-an. Dahulu, kita hanya mengenal game-game sederhana seperti Pac Man, Mario Bross, Contra, Mortal Kombat yang terdapat dalam konsol Arcade, Nintendo, Brick Game, Play Station. Game dahulu identik dengan konten yang berisikan kekerasan dan pornografi. Saat ini, game telah menjelma menjadi sesuatu permainan yang lebih kreatif, realistis, dan futuristik. Bahkan, banyak game yang didesain untuk mensimulasikan kehidupan nyata, misalnya saja game yang kami manfaatkan dalam tulisan ini: (a) The Sims ${ }^{T M}$ FreePlay, yang mensimulasikan kehidupan sosial bermasyarakat. Game ini menyuguhkan pemain (melalui avatar $^{7}$ ) sebagai pelaku dalam dunia virtual berikut aktivitas-aktivitas yang biasa dilakukan manusia, mulai dari bangun tidur, buang air, mandi, sekolah atau bekerja, membaca buku, memasak, membayar tagihan, membeli perabotan, bersosialisasi dengan teman atau tetangga, bahkan tidur malam. (b) Bridge Constructions, yang memberi kita kesempatan menjadi seorang insinyur yang bertugas membangun jembatan guna dilewati oleh berbagai sarana transportasi seperti mobil dan truk. (c) Hay Day, yang menempatkan kita pada posisi sebagai pewaris resmi sebuah peternakan sehingga kita mendapat tugas untuk mengelola lahan yang ada untuk menghasilkan komoditas dari hasil bercocok tanam seperti: wortel, gandum, tebu, jagung, kacang hijau; beternak ayam, sapi, babi, bahkan kuda; dan mengolah hasil panen dan ternak menjadi barang yang siap dikonsumsi seperti: krim, cookies, popcorn, dan gula.

\footnotetext{
${ }^{2}$ Keempat game ini merupakan koleksi penulis sehingga telah diuji-coba dan dimainkan

3 Dikembangkan oleh Electronic Arts dengan kategori usia (12+) dapat diunduh dari https://itunes.apple.com/id/app/the-sims-freeplay/id466966101? $m$ t=8

${ }^{4}$ Dikembangkan oleh Headup Games $G m b H$ \& $C o \quad K G$ dengan kategori usia (4+) dapat diunduh dari https://itunes.apple.com/id/app/bridge-constructor-playground/id578203499? $m$ t=8

${ }^{5}$ Dikembangkan oleh Supercell dengan kategori usia (4+) dapat diunduh dari https://itunes.apple.com/id/app/hayday/id $506627515 ? m t=8$

6 Dikembangkan oleh Alex CHEN dengan kategori usia (4+) dapat diunduh dari https://itunes.apple.com/id/app/virtual-dental-surgery/id744834978? $m t=8$

${ }^{7}$ Representasi visual dari karakteristik pengguna atau pemain dalam game
} 
Komoditas tersebut yang nantinya akan kita jual kepada para pelanggan kita menurut permintaan yang sebelumnya dikirimkan kepada kita. (d) Virtual Dental Surgery, yang merupakan sebuah game di mana kita berprofesi sebagai seorang dokter gigi yang selalu siap menolong para pasien dengan berbagai macam keluhan atau gangguan yang berhubungan dengan gigi, mulai dari melakukan rontgen, membius, mencabut gigi, menambal gigi, hingga menjahit gusi yang merupakan aktivitas yang akan menjadi rutinitas kita.

\section{(1) Karakteristik Dasar Gamification}

Karakteristik gamification berikut ini diadaptasi dari Erin (2013); Glover (2013); Kapp (2013); O'Donnovan (2013). Setidaknya unsur-unsur yang mayoritas terdapat dalam game antara lain: points, badges, leaderboards, level, dan scenario. Berikut masing-masing penjelasan unsur tersebut. Hal ini perlu disampaikan untuk mengindikasikan bagaimana game sukses meningkatkan antusiasme pemainnya.
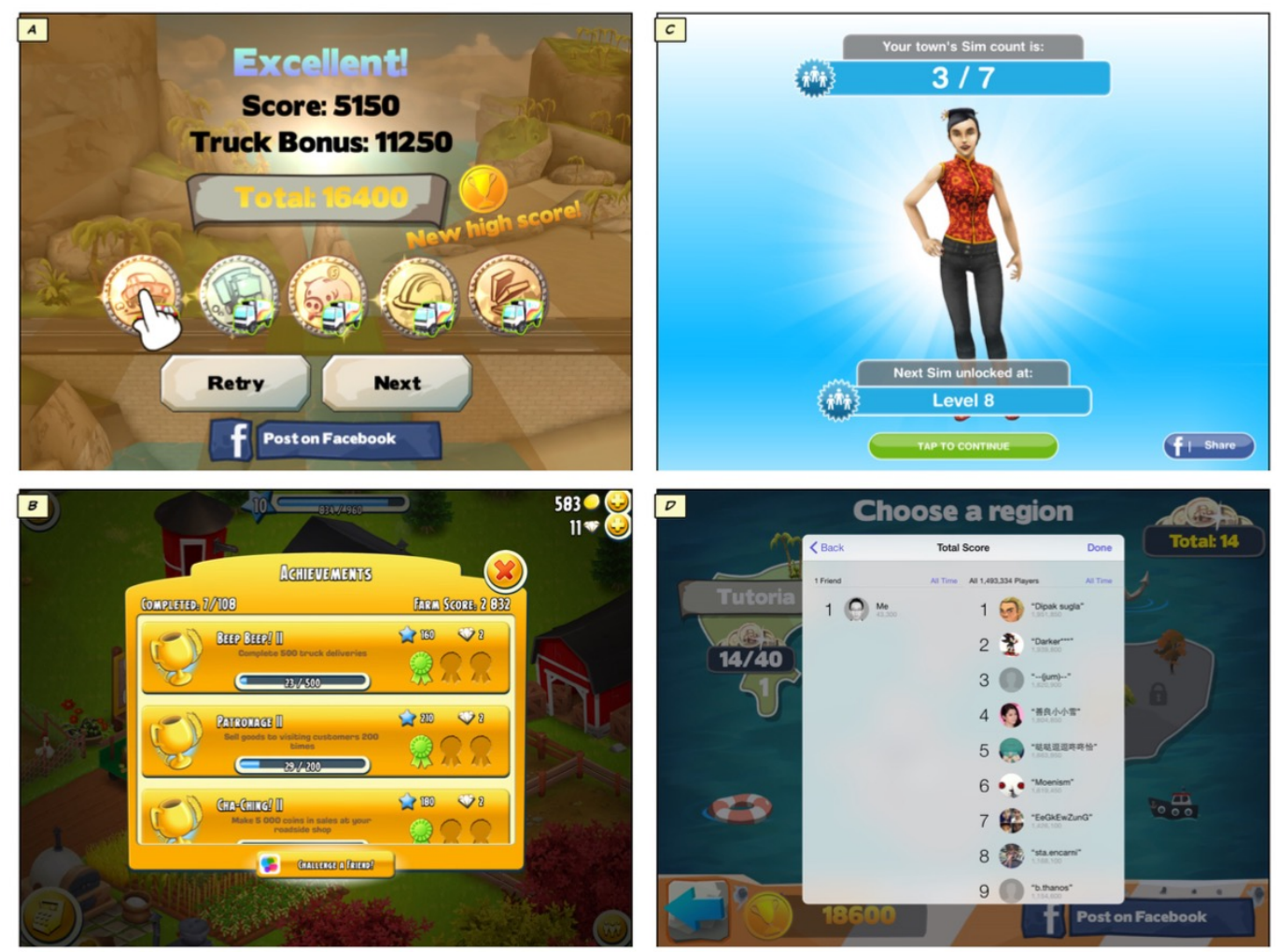

Gambar 1. Elemen-Elemen Dasar Gamification

(a) Points -ada beberapa game menyebut dengan istilah experience points (XP)- merupakan imbalan untuk tindakan baik maupun buruk (lihat Gambar 1A). Points dapat digunakan untuk menandai peningkatan dan dapat digunakan untuk membuka konten yang terkunci, bahkan dapat berfungsi sebagai mata uang yang dapat digunakan untuk membeli benda-benda virtual yang kita inginkan.

(b) Badges merupakan emblem atau lencana digital yang kita peroleh apabila telah berhasil menuntaskan misi atau tantangan tertentu (lihat Gambar 1B). Badges dapat berupa pita, tropi, atau lambang lain. Pemain biasanya mendapatkan badges untuk mengukur pencapaian di skill tertentu yang dimaksud pada game. 
(c) Leaderboards ${ }^{8}$ merupakan "a list of the individuals who have the highest scores or most points or who have achieved higher levels." (Kapp, 2013: 291). Dengan kata lain, leaderboards merupakan daftar namanama pemain peringkat atas menurut kesuksesan mereka dalam game (lihat Gambar 1D). Hal ini merupakan penunjuk perolehan points sementara. Konsep yang sama yang biasanya digunakan dalam bidang olahraga -klasemen-, tetapi lebih digunakan untuk game yang multi-player, khususnya yang dibatasi oleh waktu atau misi tertentu. Leaderboards bersifat real-time sehingga kita dapat mengetahui posisi kita secara langsung. Dengan demikian, kita mengetahui dengan pasti berapa jumlah points kita, peringkat kita, serta pemimpin (peringkat pertama) berikut perolehan points-nya. Khusus untuk game yang dimainkan dari platform iOS memiliki portal khusus untuk game yang bernama Game Center. Fitur ini merupakan portal yang berisi riwayat atau data mengenai game-game yang telah dan sedang dimainkan. Karena mendukung layanan daring (online), maka kita dapat mengurutkannya atau melakukan pengecekan ranking dalam skala global (dunia) maupun skala kecil (nasional) yang informasinya dipancarkan melalui GPS peranti kita. Selain itu, kita juga dapat melakukan sinkronisasi kepada temanteman kita melalui aplikasi Facebook terhadap game yang sama. Perolehan nilai dan ranking yang kita capai dapat kita post-kan ke dinding Facebook kita sehingga kita pun merasa bangga atas hasil tersebut. Sebagai tambahan, kita pun bisa mendapatkan komentar melalui Facebook yang tentunya merupakan wujud apresiasi teman-teman kita.

(d) Levels merupakan jenjang atau tingkat kesulitan (lihat Gambar 1C). Semakin tinggi level berarti semakin tinggi pula kesulitan serta kekompleksan misi atau tugas yang harus diselesaikan. Level 1 harus dituntaskan apabila kita ingin memainkan level 2 (meskipun ada beberapa game yang membatasi dengan beberapa level sekaligus). Intinya, ada fitur-fitur atau level-level tertentu yang terkunci (unlocked) dan belum bisa dimainkan apabila kita belum menyelesaikan misi, tugas, atau level sebelumnya.

(e) Scenario (cerita dan tema) merupakan jalan cerita yang menghidupkan permainan. Ini dibuat guna membuat game lebih menarik dan senyata mungkin, sehingga ada konteks-konteks tertentu pada sebuah tema yang terdapat pada game tertentu. Misalnya game Virtual Dental Surgery yang diawali dengan kisah seorang siswa bernama James yang gigi bawahnya tanggal karena terkena lemparan bola ketika bermain softball. Karena kecelakaan itu, James datang ke klinik untuk melakukan implan gigi palsu. Singkatnya, game dibuat senyata mungkin dengan kondisi masyarakat pada umumnya. Game tidak meminta kita melaakukan sesuatu tanpa suatu sebab. Bahkan, Prosedur Operasional Standar didesain agar mampu mensimulasikan keadaan yang sesungguhnya, misalnya sebelum memeriksa gigi, kita harus melakukan rontgen melalui penyinaran sinar-X untuk melakukan pengecekan mengenai kesehatan tulang rahangnya. Artinya, game tidaklah suatu hal yang selalu merujuk pada dunia fiktif.

Unsur-unsur (a), (b), (c), dan (d) merupakan unsur pokok karena digunakan untuk melacak atau mengukur progres atau peningkatan pemain dalam bermain game.

\section{(2) Mengapa gamification?}

Berikut penulis sampaikan efek dari hadirnya elemen-elemen dalam gamification yang dapat berimbas pada penggunanya. Keunggulan inilah yang nantinya dapat diadaptasikan dalam proses pembelajaran.

\footnotetext{
${ }^{8}$ Ada pula yang menyebutkan dengan highscores
} 

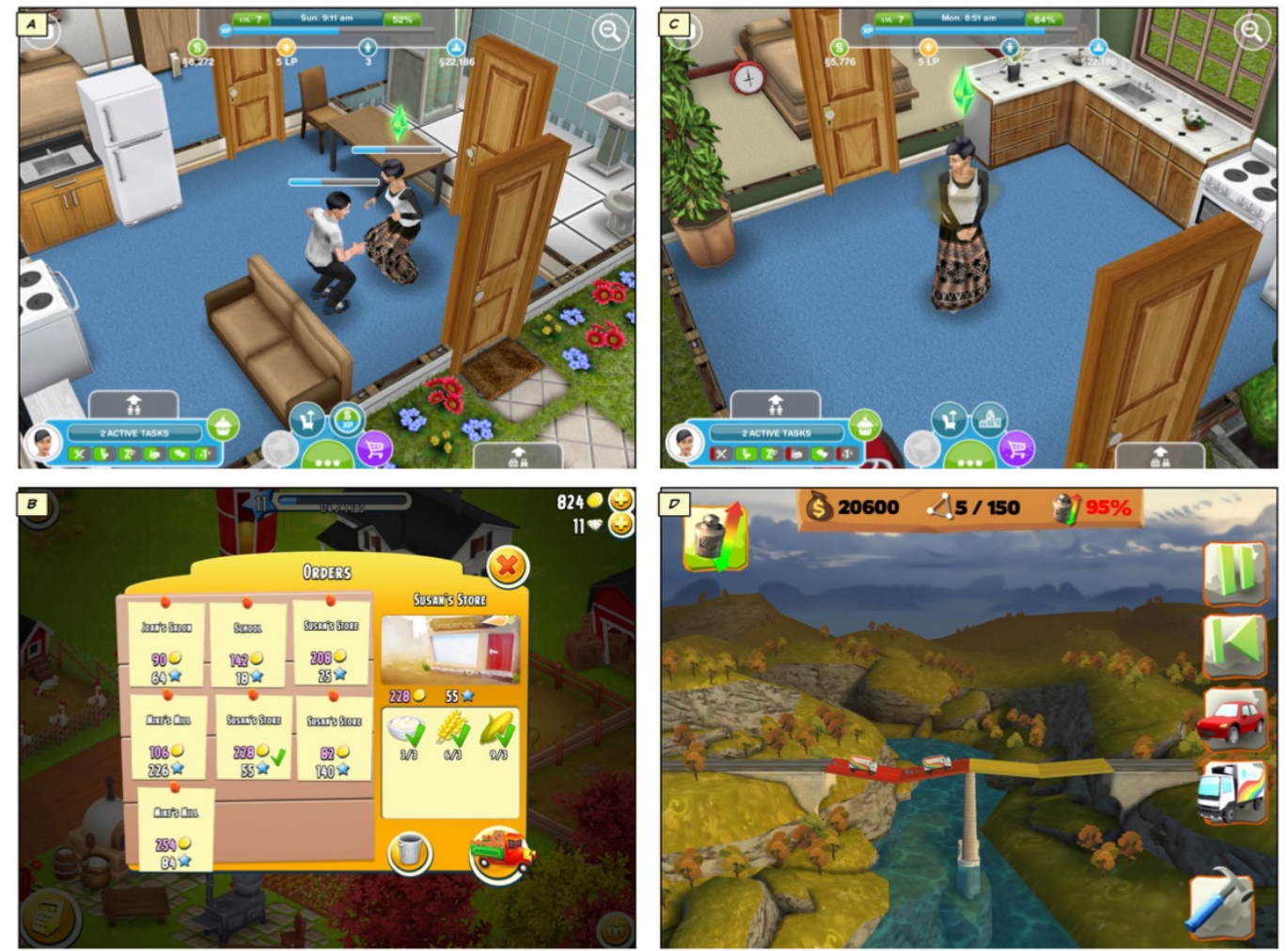

Gambar 2. Aktivitas yang Terjadi dalam Game

(a) Kompetisi and Kolaborasi

Game pada umumnya dapat dimainkan secara multi-players. Dengan demikian, kita dapat bersaing dengan pemain lain dalam satu game yang sama. Adanya Game Center dan Facebook memungkinkan kita untuk terhubung secara daring dalam rangka mendapatkan lawan atau rekan (untuk membentuk sebuah tim yang akan melawan tim lain). Selain itu, elemen-elemen gamfication seperti points, badges, levels, dan leaderboards merupakan unsur pembukti aktualisasi diri melalui game.

Kompetisi ditopang dengan adanya leaderboards yang berguna sebagai motivator yang kuat. Leaderboards pada umumnya dimanfaatkan dalam aktivitas yang kompetitif, meskipun demikian dapat pula digunakan untuk menstimulus kerja tim. Dengan adanya unsur points, badges, dan level pemain dibedakan. Para pemain yang memperoleh skor tertinggi berada di daftar paling atas. Pemain lain tentunya akan berusaha untuk mengejar ketertinggalan mereka. Inilah sebabnya mengapa game bersifat aditif atau membuat kecanduan.

Begitu pula pada game The Sims ${ }^{T M}$ FreePlay. Kita dapat menjadikan rumah virtual kita sebagai rumah yang termewah, menjadikan avatar kita sebagai avatar yang memiliki teman terbanyak, atau menjadi pemain yang menduduki level tertinggi. Itu akan kita peroleh secara bertahap karena di awal permainan, kita akan diberi modal yang sama, tidak ada perbedaan antara pemain satu dengan pemain yang lain. Ini tergantung bagaimana manajemen kita menjalani kehidupan virtual tersebut. Artinya, pemain yang lebih lama belum tentu menjadi pencetak skor tertinggi. Oleh karena itu, kompetisi di dunia game sangat tinggi karena secara naluriah, kita akan berusaha untuk mengungguli perolehan pemain lain.

Di samping kompetisi, game juga memfasilitasi kita untuk terhubung dengan pemain lain dalam rangka bekerja sama atau menjalin hubungan. Dalam game The Sims ${ }^{T M}$ FreePlay kita dapat berkunjung ke rumah virtual pemain lain, memanfaatkan perabotan mereka, berinteraksi dengan avatar mereka, atau 
menjalin pertemanan (lihat Gambar 2A). Bahkan, ada sebuah misi di mana kita diminta untuk bertindak romantis guna menjalin percintaan dengan avatar lain. Hal inilah yang secara tidak langsung mengajarkan kita untuk berkolaborasi dengan pemain lain dalam tujuan yang sama.

\section{(b) Tujuan Jelas, Tantangan yang Adil}

Game didesain dengan misi atau tujuan yang sangat jelas. Oleh karena itu, apapun yang kita lakukan tidak akan menyelesaikan level atau misi tertentu kecuali apa yang diminta atau diperintahkan dipenuhi. Sebagai contoh pada game Hay Day, saat kita diminta untuk memenuhi toko milik Susan (kita berperan sebagai penyuplai kebutuhan dasarnya) berupa 3 gandum, 3 jagung, dan 3 krim, maka Susan tidak akan menawarkan permintaan lain kepada kita sebelum tugas tersebut terpenuhi (lihat Gambar $\mathbf{2 B}$ ). Di samping itu, masih ada pula pembeli partai kecil (eceran) yang akan datang sewaktu-waktu untuk membeli kebutuhannya dari kita. Stok barang pun harus kita jaga karena juga merupakan benih dari tanamantanaman tersebut yang harus kita semaikan. Apabila benih habis, maka kita tidak dapat bertani dan panen. Dengan demikian, kita akan berusaha keras untuk menuntaskan pekerjaan secepat mungkin agar secepatnya mendapatkan misi baru. Tantangan ini melatih kita untuk menerapkan strategi yang baik sehingga misi (permasalahan) yang ada dapat kita selesaikan melalui learning by doing.

\section{(c) Feedback yang Kontinyu}

Feedback sangat dibutuhkan untuk mengetahui hasil atau imbas dari aktivitas (pekerjaan) yang kita lakukan. Bagian mana yang telah kita lakukan dengan benar dan bagian mana yang perlu kita dibenahi. Selain itu, feedback juga dapat berfungsi ganda sebagai motivator (yang dalam dunia pendidikan kita kenal dengan istilah penguatan). Bentuknya dapat berupa verbal maupun non-verbal. Dalam kenyatannya, saat mengoreksi atau mengevaluasi hasil kerja siswa dibutuhkan beberapa waktu, hari, bahkan minggu. Belum lagi penguatan yang kita berikan ke siswa pun terbatas (tidak dapat dipenuhi satu per satu kepada siswa).

Sebaliknya, game mampu memberikan feedback secara serta-merta dan kontinyu, game The Sims misalnya. Sebagaimana kita ketahui, setiap game memiliki aturan main tersendiri. Aturan tersebut dapat dipelajari pemain tanpa harus membaca dan memahami buku manual. Secara otomatis, game menghadirkan opsi, menu, atau fitur tertentu atas apa yang kita lakukan. Misalnya saat kita memainkan game The Sims ini. Avatar (pemain dalam game) akan menyesuaikan progress bar yang ada, yang berdasar pada segala aktivitas kita. Apabila indikator tidur kita menipis dan kita tidak segera menjalankannya untuk beristirahat, maka avatar akan merasa pusing. Apabila indikator kebersihan menipis dan tidak segera membersihkan diri, maka muncul bau yang tidak sedap di sekitar tubuh kita (lihat Gambar $2 \mathrm{C}$ ). Apabila kita jarang membaca buku, maka nilai rapor kita akan jelek. Feedback tidak hanya diberikan apabila kita melakukan sesuatu yang tidak sesuai permintaan sistem. Feedback muncul ketika kita melakukan sesuatu dengan benar atau baik, misalnya ketika kita berangkat kerja disiplin tepat waktu, maka beberapa saat kemudian kita akan dipromosikan untuk naik jabatan. Bahkan, bonus seperti Simoleons (mata uang dalam game ini) dan barang-barang lain menjadi hak kita.

Singkatnya, game menawarkan feedback yang melimpah dari segala detil aktivitas yang dilakukan. Feedback akan didapatkan saat kita melakukan sesuatu dengan benar dan juga yang kurang tepat. Secara otomatis, feedback akan muncul dengan segera melalui berbagai macam bentuk: visual dan audio visual. Bukti konkrit feedback dalam game adalah pemberian points dan badges serta peningkatan level kepada para pemain. 


\section{(d) Pilihan dan Kesempatan}

Dalam proses pembelajaran di kelas, siswa terkadang tidak difasilitasi dengan berbagai model belajar yang dapat mereka pilih sesuai dengan karakteristik mereka. Kebebasan inilah yang dapat kita dapatkan dalam game.

Sebagaimana telah disebutkan bahwa game terdiri dari berbagai macam level dan misi yang harus diselesaikan. Game Bridge Construction memberi kita misi untuk menjadi perancang jembatan yang aman untuk dilewati kendaraan. Selain aman, sebisa mungkin biaya pembangunan jembatan tidak melebihi anggaran yang disediakan (lihat Gambar 2D). Dengan material yang disediakan kita diminta untuk memenuhi setiap tantangan yang ada. Tantangan ini dibatasi oleh biaya dan daya tahan jembatan. Artinya, kita bebas membangun struktur jembatan dengan material yang kita pilih (material baja misalnya dengan daya tahan yang lebih kuat, tetapi biaya yang agak mahal; material kayu dengan harga yang lebih murah, tetapi dengan resiko berupa daya tahan yang lebih lemah; atau kita bisa menguatkannya dengan bantuan kawat besi). Bentuknya pun dapat kita variasikan, seperti dengan rangka utama berbentuk segitiga, menambahkan deck atau geladak, tiang pondasi dengan tinggi tertentu, serta penambahan gerbang dan kabel penarik. Artinya, pemain bebas memilih seperti apa jembatan yang akan dibuatnya asalkan sesuai dengan kriteria yang diminta.

Di lain pihak, apabila setelah melalui proses uji coba dengan beberapa kendaraan yang melintas ternyata jembatan tersebut ambruk, kita dapat mengulang game tersebut di level yang sama. Bahkan, kita dapat mengulang level-level sebelumnya untuk mendapatkan poin yang lebih tinggi dengan jalan membuat jembatan yang seringan dan semurah mungkin.

Dalam game, kita dapat memilih segala opsi yang ada karena 100\% kontrol permainan ada di tangan pemain. Kita dapat mencoba segala pilihan sesuai apa yang kita mau. Artinya, kita memiliki kesempatan yang besar untuk mengeksplorasi dan memahami game tersebut dengan baik.

\section{(e) Investasi dalam Kekalahan (Kegagalan)}

Kegagalan seringkali menjadi momok bagi peserta didik. Jawaban yang kurang tepat atau kegagalan dalam sebuah tes, bisa menjadi pemicu menurunnya antusiasme dan motivasi mereka dalam belajar. Jarang sekali penulis dapati sebuah kegagalan yang diadaptasi sebagai sesuatu yang positif dalam rangka pembenahan diri.

Bertolak belakang dengan hal tersebut, game bagi seorang pemain merupakan suatu tantangan yang harus dikalahkan atau ditaklukkan. Sering ditemui bahwa seorang pemain tidak akan puas setelah menyelesaikan misi atau level pada game tertentu, meskipun kegagalan demi kegagalan harus mereka dapatkan. Artinya, kegagalan dalam game akan diadaptasi secara baik oleh pemain. Tentunya, pemain tidak akan mengulangi kesalahan yang sama. Dengan demikian, mereka akan mencari solusi lain demi mencapai keberhasilan. Solusi tersebut didapatkan dari memahami dan mempelajari kesalahan yang sebelumnya dilakukan.

Dalam game Virtual Dental Surgery, kita akan dihadapkan pada prosedur-prosedur dan alat-alat tertentu yang berkaitan dengan bidang medis, khususnya kedokteran gigi. Prosedur tersebut tentunya harus dilakukan dengan berurutan dan benar. Alat-alat yang digunakan pun harus tepat, misalnya jika kita ingin melakukan pengecekan melalui sinar-X kita harus memberikan pasien positioner, berupa alat yang ditaruh pada mulut, saat pertama kali memberikan tindakan kita diharuskan membubuhkan numbling gel pada gusi sebelum memberikan injeksi, untuk membantu mengangkat gigi kita dapat memanfaatkan elevator yang kemudian dilanjutkan dengan menggunakan forceps, begitu pula seterusnya. Apabila kita 
melakukan kesalahan, kita akan mendapatkan konsekuensi berupa pengurangan poin (-100) dan denyut jantung pasien akan semakin tinggi (meningkat). Semakin banyak kesalahan yang kita lakukan akan berakibat pada ketidakstabilan pasien yang berujung pada gagalnya operasi.

Peserta didik memerlukan pengalaman kegagalan untuk belajar, yaitu gagal dengan melalaikan sebuah prosedur, keliru dalam menggunakan alat, menerapkan metode yang salah, atau berada dalam masalah serius. Dalam kehidupan nyata, kegagalan umumnya terkait dengan situasi yang beresiko tinggi, di mana menerapkan alat yang salah bisa mengakibatkan kematian. Game dapat membantu kita mengurangi kesalahan yang akan kita lakukan di dunia nyata melalui berbagai macam simulasi.

\section{Simpulan}

Sebuah game yang efektif adalah game yang memotivasi, aditif, dan menghadirkan stimulasi melalui misi-misi singkatnya. Dengan demikian, pemain dapat gagal dan mencoba lagi hingga berhasil. Di sekolah, apabila salah seorang siswa gagal dalam sebuah tes atau ujian, memungkinkannya untuk gagal dalam keseluruhan pelajaran.

Sebagai simpulan, penulis berpendapat bahwa: (1) Game dapat membuat kita menjadi orang lain (melakoni) profesi tertentu. Hal ini memberikan kita kesempatan untuk menggali wawasan sebanyakbanyaknya dan memahami bagaimana melakukan pekerjaan dengan baik dan benar. (2) Game tidak hanya sebatas kepuasan pemain dalam mengisi waktu luangnya. Game membuat orang menjadi cerdas melalui tugas atau misi-misi yang disediakan dalam permainan tersebut. Dan yang terakhir, (3) Gamification melibatkan sisi kognitif dan psikomotor seseorang. Artinya, game -yang mensimulasikan keterampilan kognitif dan motorik- yang diperlukan dalam situasi dunia nyata lebih mungkin untuk mengarah pada hasil belajar yang sukses daripada game yang lebih abstrak.

Dalam pandangan saya, gamification intinya adalah bagaimana kita memberikan motivasi, penghargaan atas capaian tertentu kepada para siswa setelah berhasil memecahkan sebuah masalah.

\section{Saran/rekomendasi}

Di akhir tulisan ini, penulis memberikan beberapa saran/rekomendasi bagi orang-orang yang terlibat dalam dunia pendidikan, khususnya pengajar, peserta didik, dan orang tua. Teknologi digital, dalam hal ini game sudah selayaknya dapat kita manfaatkan dalam tujuan-tujuan positif di bidang pendidikan karena selama ini game layaknya buah simalakama, "disukai anak, dibenci orang tua dan guru". Untuk itu, penulis menawarkan beberapa saran berikut.

\section{(1) Bagi Pengajar}

Buatlah materi pelajaranmu layaknya sebuah game! Anda dapat melakukannya dengan dua cara: (a) mensimulasikan dari dunia nyata ke maya; atau mengadaptasi dunia maya ke nyata. Cara pertama dapat Anda tempuh dengan mendesain materi pembelajaran ke dalam (video) game agar lebih menarik. Bubuhi dengan segala permasalahan yang berkaitan dengan tema tersebut. Jikalau itu menguras biaya yang terlampau tinggi, coba telusuri game-game yang berhubungan dengan topik Anda. Adopsikan beberapa game yang sesuai dalam materi. Itu akan menumbuhkan daya saing yang sehat di antara siswa. Atau yang lebih mudah lagi dengan cara kedua. Adaptasikan unsur game dalam pembelajaran Anda. Mulailah mengubah nilai atau bobot nilai dengan sistem poin, misalnya nilai 100 dengan poin 100.000 (atau bobot $10 \%$ dengan poin 10.000). Berikan misi pembelajaran yang lebih terstruktur dengan jelas, bervariatif, serta menyuguhkan tantangan yang lebih menarik lagi, misalnya berikan poin pada siswa yang datang paling 
awal, yang membaca buku hingga mencapai halaman tertentu, yang berkunjung ke perpustakaan, yang menelusuri halaman situs yang bermanfaat, atau yang mem-post-kan gambar yang terkait dengan tema pembelajaran sehingga Anda dan siswa lain bisa memberikan komentar (feedback) kapan pun dan dari mana pun. Motivasi mereka dengan memberikan badge atau pin yang ditempel di kerah atau lengan baju mereka apabila mereka berhasil mencapai prestasi tertentu, misalnya "siswa terpopuler" bagi siswa yang berkunjung minimal sekali sebulan ke perpustakaan atau yang tiga kali mengunggah gambar atau video sesuai tema! Buat pula sistem level semisal: "profesor", "doktor", "magister", "sarjana", atau "diploma" bagi siswa menurut perolehan poin dan misi yang telah dituntaskan. Umumkan pada leaderboards atau papan ranking yang ditaruh pada tempat strategis sehingga mereka dapat mengecek update capaian yang telah mereka tempuh. Dan mulailah bergabung dalam permainan mereka!

\section{(2) Bagi Pelajar}

Tidak perlu ragu! Tetaplah bermain game dan menangkan game-mu! Akan tetapi, ingat jangan curang! Belajar dari kesalahan yang lalu lakukan sehingga bisa mencatatkan namamu di peringkat teratas. Berbagilah trik dengan rekanmu! Dan terakhir, manajemen waktumu dengan baik agar tidak dimarahi orang tuamu!

\section{(3) Bagi Orang Tua}

Lebih berbaik sangka apabila mendapati putra-putri Anda yang sedang bermain game. Yakini bahwa mereka bermain sambil belajar. Luangkan waktu Anda untuk mengamati bagaimana cara mereka menyelesaikan misi (masalah) yang ada, niscaya itu akan membuat Anda takjub. Apabila Anda tidak percaya, silakan coba mainkan game putra Anda. Bandingkan permainan (bagaimana Anda menyelesaikan misi) Anda dengan putra Anda. Jangan lupa, pastikan mereka memilih kategori game yang tepat berdasarkan usianya.

\section{(4) Bagi Pembaca}

Ini adalah bonus bagi para pembaca. Gamification sebenarnya tidak hanya dapat diaplikasikan di pendidikan. Mekanisme ini dapat dimanfaatkan dalam setiap aktivitas kehidupan manusia, misalnya meningkatkan kinerja karyawan, transaksi jual-beli untuk meningkatkan daya beli konsumen, dan lain sebagainya. Untuk itu, desainlah gamification pada dunia yang Anda geluti. Dan terakhir, terima kasih dan selamat Anda mendapatkan badges atas niat baik Anda membaca tulisan ini.

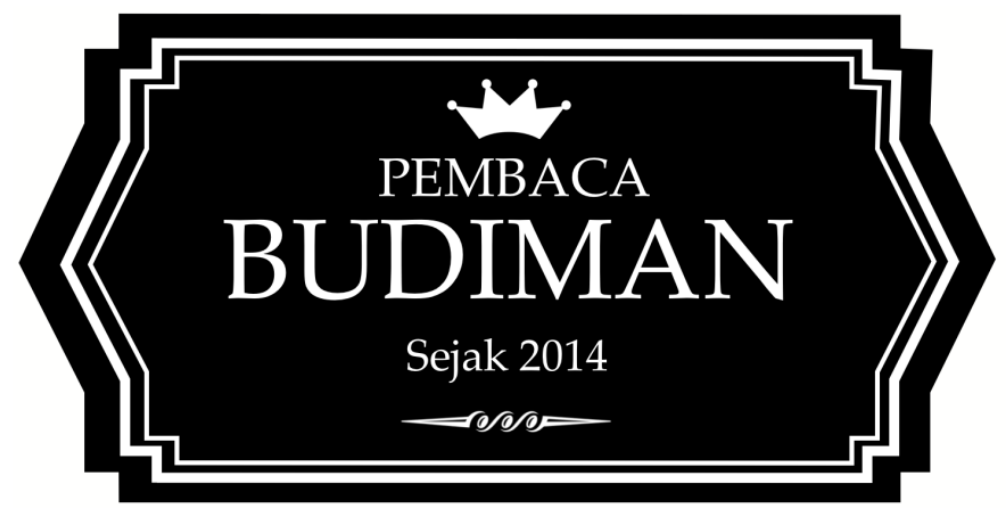

Gambar 3. Badge bagi Pembaca yang Telah Meluangkan Waktunya 


\section{DAFTAR PUSTAKA}

Arum, Rachma Nur Kartika dan Achmad Lutfi. 2012. "Memotivasi Siswa Belajar Materi Asam Basa melalui Media Permainan Rangking One Chemistry Quiz". Dalam Unesa Journal of Chemical Education Vol. 1, No. 1, hal. 174-179 Mei 2012.

Erenli, Kai. 2013. "The Impact of Gamification: Recommending Education Scenarios". Dalam jurnal iJET Volume 8, Special Issue 1: "ICL2O12", January 2013.

Fitz-Walter, Zachary, Tjondronegoro, Dian W., \& Wyeth, Peta. 2011. "Orientation passport: using gamification to engage university students". Dalam Proceedings of the 23rd Australian ComputerHuman Interaction Conference, ACM, Australian National University, Canberra, ACT.

Glover, Ian. 2013. "Play as you learn: gamification as a technique for motivating learners". Dalam Proceedings of World Conference on Educational Multimedia, Hypermedia and Telecommunications 2013 .

González, C. and Area M. 2013. "Breaking the Rules: Gamification of Learning and Educational Materials". Dalam Proceedings of the 2nd International Workshop on Interaction Design in Educational Environments, hal. 47-53

Hamari, J., Koivisto, J., \& Sarsa, H. 2014. "Does Gamification Work? - A Literature Review of Empirical Studies on Gamification". Dalam Proceedings of the 47th Hawaii International Conference on System Sciences, Hawaii, USA, January 6-9, 2014.

Harris, Scot dan Kevin O'Gorman. 2014. Mastering Gamification: Customer Engagement in 30 Days. Birmingham: Impackt Publishing Ltd.

Huotari, Kai dan Juho Hamari. 2012. "Defining Gamification: A Service Marketing Perspective". dalam MindTrek 2012, October 3-5, 2012, Tampere, FINLAND.

Juul, J. (2003). "The Game, the Player, the World: Looking for a Heart of Gameness". Dalam Proceedings of Level Up: Digital Games Research Conference, hal. 30-45. Diakses: 2/11/2014 melalui http://www.jesperjuul.net/text/gameplayerworld/

Kapp, Karl M. 2013. The Gamification of Learning and Instruction Fieldbook. San Fransisco: Wiley.

Landers, Richard N. dan Rachel C. Callan. 2011. "Casual Social Games as Serious Games: The Psychology of Gamification in Undergraduate Education and Employee Training”. Dalam M. Ma et al. (eds.). Serious Games and Edutainment Applications. London: Springer.

Miller, Craig. 2013. "The Gamification Of Education". Dalam Developments in Business Simulation and Experiential Learning, volume 40, 2013

Nugrahani, Rahina. "Media Pembelajaran Berbasis Visual Berbentuk Permainan Ular Tangga untuk Meningkatkan Kualitas Belajar Mengajar di Sekolah Dasar”. Dalam Lembaran Ilmu Kependidikan Jilid 36, NO. 1, JUNI 2007.

Nugroho, Aris Prasetyo, Trustho Raharjo, dan Daru Wahyuningsih. 2013. "Pengembangan Media Pembelajaran Fisika Menggunakan Permainan Ular Tangga Ditinjau dari Motivasi Belajar Siswa Kelas VIII Materi Gaya”. Dalam Jurnal Pendidikan Fisika (2013) Vol.1 No.1. hal. 11-18.

O'Donovan, Siobhan, James Gain, dan Patrick Marais. 2013. "A Case Study in the Gamification of a University-level Games Development Course". dalam SAICSIT '13, October 07-o9 2013, East London, South Africa.

Reiners, T., Wood, L. C., Chang, V., Guetl, C., Herrington, J., Gregory, S., \& Teräs, H. 2012. "Operationalising gamification in an educational authentic environment". Dalam Kommers, Piet, Issa, Tomayess, \& Isaías, Pedro (Eds.), IADIS International Conference on Internet Technologies \& Society 2012. hal. 
93-100. Disajikan pada International Conference on Internet Technologies \& Society 2012, Perth, Australia: IADIS Press.

Robert Ormsby, Robin Daniel \& Marka Ormsby. 2011. Preparing for the Future with Games for Learning: Using Video Games and Simulat ions to Engage Students in Science, Technology, Engineering, and Math, Ast ropolit ics, 9:2-3, hal. 150-164.

Tzouvara, K. and Zaharias, P. 2013. "Towards a framework for applying Gamification in Education". Dalam Proceedings of the 7 th International Conference in Open and Distance Learning (ICODL 2013).

Zichermann, Gabe. 2011. Gamification by Design. O'Reilly Media. iBooks. 